\title{
Anomalous Resistivity in Vanadium-Doped Semi-Insulating 4H-SiC Wafers
}

\author{
Xianglong Yang $\cdot$ Kun Yang $\cdot$ Yingxin Cui $\cdot$ Yan Peng $\cdot$ Xiufang Chen $\cdot$ Xuejian Xie $\cdot$ Xiaobo Hu \\ Xiangang Xu
}

Received: 26 July 2013/Revised: 16 April 2014/Published online: 11 September 2014

(C) The Chinese Society for Metals and Springer-Verlag Berlin Heidelberg 2014

\begin{abstract}
The resistivities of vanadium-doped semi-insulating $4 \mathrm{H}-\mathrm{SiC}$ wafers were measured by a contactless resistivity measurement system. Anomalous resistivity was found in semi-insulating $4 \mathrm{H}-\mathrm{SiC}$ wafer. Raman spectra of semi-insulating $4 \mathrm{H}-\mathrm{SiC}$ wafer indicated that the anomalous resistivity was caused by polytype inclusion. Based on the activation energies of different $\mathrm{SiC}$ polytypes calculated from resistivity versus temperature data measured by COREMA-VT, the resistivities in the vanadium-doped semi-insulating $4 \mathrm{H}-\mathrm{SiC}$ wafer with $6 \mathrm{H}$ polytype inclusion were calculated. The calculated resistivities are quite consistent with the measured resistivities. Furthermore, the compensation mechanism for the formation of anomalous resistivity was proposed.
\end{abstract}

\section{KEY WORDS: SiC; Anomalous resistivity; Polytype inclusion; Activation energy; Compensation mechanism}

\section{Introduction}

Silicon carbide $(\mathrm{SiC})$ is an important wide bandgap semiconductor material and can be used as the substrate for the fabrication of high temperature, high-power, and highfrequency electronic devices [1,2] due to a combination of superior physical properties [3], including high saturated drift velocity, high electric field breakdown strength, and high thermal conductivity. It is also the ideal substrate for the fabrication of gallium nitride-based photoelectronic devices [4]. The physical vapor transport (PVT) is the most successful method for growth of bulk SiC single crystals.

Available online at http://link.springer.com/journal/40195

X. Yang $\cdot$ K. Yang $\cdot$ Y. Cui $\cdot$ Y. Peng $\cdot$ X. Chen $\cdot$ X. Xie

X. Hu $(\bowtie) \cdot X . X u(\bowtie)$

State Key Laboratory of Crystal Materials, Shandong University,

Jinan 250100, China

e-mail: xbhu@sdu.edu.cn

$\mathrm{X} . \mathrm{Xu}$

e-mail: xxu@sdu.edu.cn
As well known, there are more than 200 polytypes for $\mathrm{SiC}$ crystals [5]. Among of them, only three kinds of bulk SiC single crystals, i.e., $6 \mathrm{H}, 4 \mathrm{H}$, and $15 \mathrm{R}$ polytypes could be obtained up to now.

For microwave power device application, the $4 \mathrm{H}-\mathrm{SiC}$ polytype is preferable because it has a wider bandgap and higher electron mobility than $6 \mathrm{H}-\mathrm{SiC}$. A key requirement for low-loss devices operating at microwave frequencies is an electrically passive. Therefore, semi-insulating (SI) substrate, which exhibits low dielectric loss, is preferably used for the fabrication of microwave device. Intentional vanadium doping into $4 \mathrm{H}-\mathrm{SiC}$ single crystal is an effective way to obtain the SI single crystal [6]. In past, electron paramagnetic resonance (EPR) [7], photo-EPR [8], temperature-dependent Hall effect (TDH), and optical absorption [9] were used to investigate deep levels of impurities in $\mathrm{SiC}$ single crystals. It has been found that vanadium atoms often occupy silicon sites. As a consequence, two new levels within the $\mathrm{SiC}$ bandgap were produced. It has been determined that the $\mathrm{V}^{3+/ 4+}$ acceptor levels are at $E_{\mathrm{C}}=(0.85 \pm 0.03) \mathrm{eV}$ in $6 \mathrm{H}-\mathrm{SiC}$ and $E_{\mathrm{C}}=(1.11 \pm 0.08) \mathrm{eV}$ in $4 \mathrm{H}-\mathrm{SiC}$, whereas the $\mathrm{V}^{4+/ 5+}$ 
donor levels are at $E_{\mathrm{C}}=(1.54 \pm 0.06) \mathrm{eV}$ in $6 \mathrm{H}-\mathrm{SiC}$ and $E_{\mathrm{C}}=(1.57 \pm 0.09) \mathrm{eV}$ in $4 \mathrm{H}-\mathrm{SiC}[8,9]$.

For vanadium-doped $4 \mathrm{H}-\mathrm{SiC}$, resistivity is one of the most important parameters. In a routine resistivity measurement of vanadium-doped $\mathrm{SI} 4 \mathrm{H}-\mathrm{SiC}$, it was found that the resistivities for most substrates were always above $1 \times 10^{12} \Omega \mathrm{cm}$. Sometimes there exists an anomalous resistivity area (resistivity ranges from $1 \times 10^{10}$ to $1 \times 10^{11} \Omega \mathrm{cm}$ ) in vanadium-doped SI $4 \mathrm{H}-\mathrm{SiC}$ wafers. Furthermore, during PVT growth process, $4 \mathrm{H}-\mathrm{SiC}$ polytype is often unstable since it can easily transform to another polytype, such as $6 \mathrm{H}$ and $15 \mathrm{R}$ polytypes. The existence of these foreign polytypes will deteriorate the electrical characteristic of $\mathrm{SiC}$ as an electronic materials [10]. Therefore, it is important to keep the stability of $4 \mathrm{H}-\mathrm{SiC}$ polytype during PVT growth so that the qualified $4 \mathrm{H}-\mathrm{SiC}$ single crystals for microwave device application can be obtained. As for the formation mechanism of foreign polytypes, a feasible explanation is that the formation energy differences between these polytypes are very low [11].

In this work, we try to reveal the relationship between anomalous resistivity and polytype inclusion in vanadiumdoped SI 4H-SiC wafers by means of Raman spectroscopy and contactless resistivity measurement system. Based on the temperature dependent resistivity [12] of $4 \mathrm{H}-\mathrm{SiC}$ wafer, the compensation mechanism for the formation of anomalous resistivity in $4 \mathrm{H}-\mathrm{SiC}$ wafer was proposed.

\section{Experimental}

Vanadium-doped $4 \mathrm{H}-\mathrm{SiC}$ single crystals were grown by PVT technology at our laboratory. After standard semiconductor substrate processing, the $4 \mathrm{H}-\mathrm{SiC}$ wafers were obtained. The resistivity mapping of the vanadium-doped SI $4 \mathrm{H}-\mathrm{SiC}$ wafer was performed by using COREMA-WT, which is an innovative contactless resistivity measurement technique. A precision horizontal $x-y$ stage serves to translate the wafer underneath the probe in order to generate a resistivity mapping. A Raman spectroscope (LabRAM HR system of Horiba Jobin-Yvon, $532 \mathrm{~nm}$ solid laser source) was used to measure the Raman spectra of $4 \mathrm{H}-\mathrm{SiC}$ wafers and explore the origin of anomalous resistivity. The local activation energy $E_{\mathrm{a}}$ is calculated from the Arrhenius plot of $\rho$ versus $1,000 / T$ which was measured by COREMA-VT. Both $6 \mathrm{H}$ and $15 \mathrm{R}$ polytype inclusions in a vanadium-doped SI $4 \mathrm{H}-\mathrm{SiC}$ wafer have been detected by Raman mapping.

\section{Results and Discussion}

Figure 1 shows a typical resistivity mapping of the vanadium-doped SI $4 \mathrm{H}-\mathrm{SiC}$ wafers. The red area corresponds to

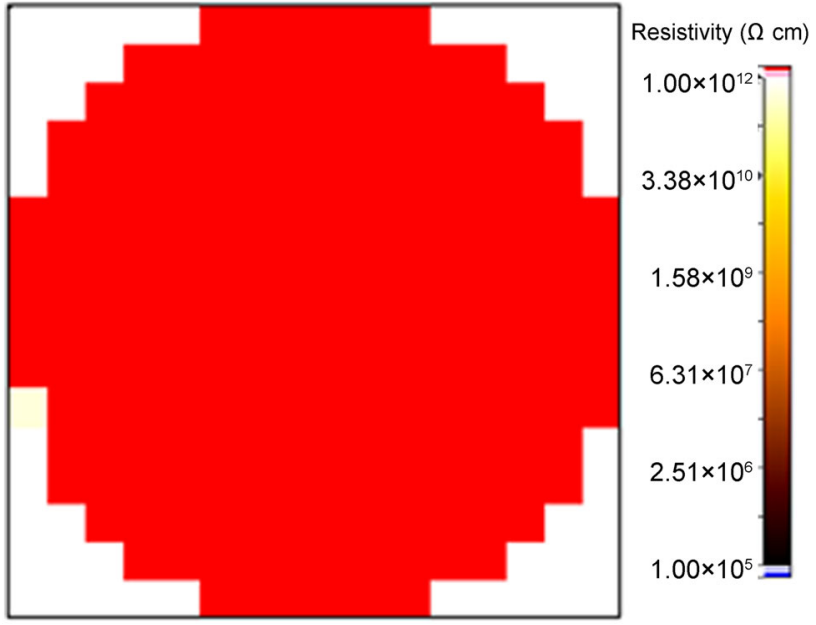

Fig. 1 Typical resistivity mapping of vanadium-doped semi-insulating $4 \mathrm{H}-\mathrm{SiC}$ wafer

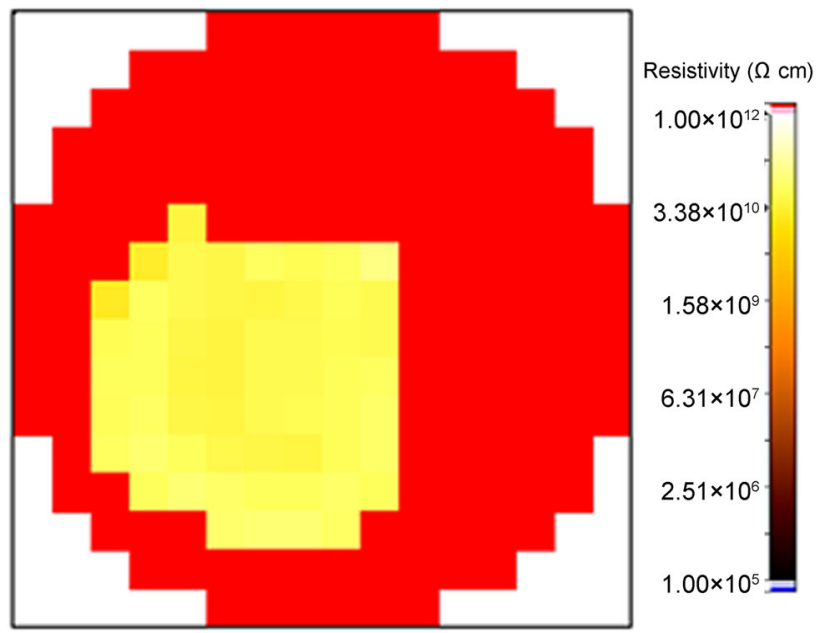

Fig. 2 Anomalous resistivity mapping of vanadium-doped semiinsulating $4 \mathrm{H}-\mathrm{SiC}$ wafer

a high resistivity greater than $1 \times 10^{12} \Omega \mathrm{cm}$. Figure 2 illustrates an anomalous resistivity mapping of vanadiumdoped SI 4H-SiC wafers in which the yellow area represents the resistivity in the range of $1 \times 10^{10}$ $1 \times 10^{11} \Omega \mathrm{cm}$.

In order to investigate the origin of anomalous resistivity area in the vanadium-doped SI $4 \mathrm{H}-\mathrm{SiC}$ wafer, Raman mapping and spectra for the $\mathrm{SI} 4 \mathrm{H}-\mathrm{SiC}$ wafer are shown in Fig. 3. As well known, the one-phonon Raman spectra of $6 \mathrm{H}-, 4 \mathrm{H}-$, and other polytypes of $\mathrm{SiC}$ can be attributed by the folding of the Brillouin zone due to the polytype behavior of $\mathrm{SiC}[13,14]$. Because different $\mathrm{SiC}$ polytypes differ by the length of the $c$-axis, only the Brillouin zone in the $\Gamma-L$ direction is affected. This folding makes modes 

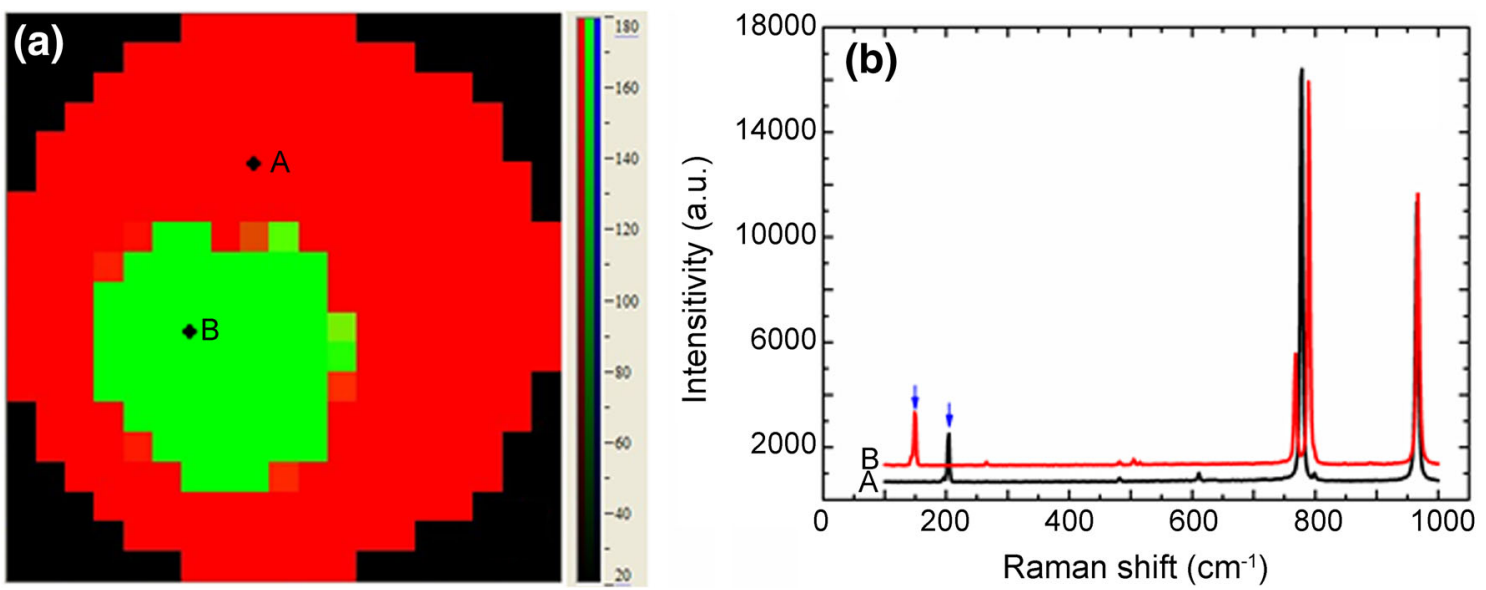

Fig. 3 Raman mapping a and Raman spectra of $\mathrm{SI} 4 \mathrm{H}-\mathrm{SiC}$ wafer corresponding to the positions $A, B$ in $\mathbf{a}, \mathbf{b}$

away from the $\Gamma$ point visible in the one-phonon Raman spectrum. Since the folded modes of transverse acoustic (FTA) bands (marked by blue arrows in Fig. 3b) are very narrow and related to the period of the SiC polytype, they can be used to identify easily the polytype structure. The FTA modes in the $4 \mathrm{H}, 6 \mathrm{H}$, and $15 \mathrm{R}$ polytypes are at about 204, 150, and $173 \mathrm{~cm}^{-1}$, respectively. The Raman mapping in Fig. 3a is fitted by the peak positions of FTA bands. According to the Raman spectra A and B in Fig. 3b which originate from the contribution of areas A and B in Fig. 3a, it is known that area $\mathrm{A}$ is pure $4 \mathrm{H}-\mathrm{SiC}$ polytype while area $\mathrm{B}$ contains $6 \mathrm{H}-\mathrm{SiC}$ polytype inclusion.

It can be seen clearly that the location of the lower resistivity area $\left(1 \times 10^{10}-1 \times 10^{11} \Omega \mathrm{cm}\right)$ in Fig. 2 agrees well with the location of the $6 \mathrm{H}$ polytype inclusion in Fig. 3a. It is noted that the profile of the lower resistivity area (Fig. 2) is different from that of the $6 \mathrm{H}$ polytype area (Fig. 3a), which can be attributed to the different scanning resolutions for two measurement methods. Since the COREMA-WT sensor is a spot with $1 \mathrm{~mm}$ in diameter, and the resistivity data are obtained by a parallel plate sensor sequentially probing a 1-mm diameter spot of the wafer material. In contrast, the Raman mapping is obtained with a laser spot sequentially scanning the wafer in an incremental spacing of $4,000 \mu \mathrm{m}$. Therefore, the scanning resolutions for two measurement methods are actually different.

For a semiconductor material, the resistivity depends on the Fermi level position in the bandgap. Moreover, the resistivity activation energy gives the position of the dominant levels pinning the Fermi level. Therefore, if the activation energy is obtained, the resistivity of semiconductor material can be calculated.

A COREMA-VT instrument was used to measure the activation energy. Figure 4 is the Arrhenius plot of $\rho$ versus $1,000 / T$ of vanadium-doped $\mathrm{SI} 4 \mathrm{H}-\mathrm{SiC}$ with $6 \mathrm{H}$ polytype inclusion measured by COREMA-VT. The Arrhenius equation can be described by the following equation:
$E_{\mathrm{a}}=\left(k T_{1} T_{2}\right) /\left(T_{2}-T_{1}\right) \times \ln \left[\rho\left(T_{1}\right) / \rho\left(T_{2}\right)\right]$.

From the linear portions of the curves in Fig. 4a and b, an activation energy was calculated of approximately $1.076 \mathrm{eV}$ for $4 \mathrm{H}-\mathrm{SiC}$ and $0.81 \mathrm{eV}$ for $6 \mathrm{H}-\mathrm{SiC}$, consistent with previously determined ionization energy values of the vanadium acceptor level, $\mathrm{V}^{3+/ 4+}$ in vanadium-doped $4 \mathrm{H}$ - and $6 \mathrm{H}-\mathrm{SiC}$ [9]. The little activation energy difference between our calculated and the previously published might be due to the facts that impurity concentrations, the crystal quality, and the local strain among samples were different [9]. As a result, the Fermi level in vanadium-doped $\mathrm{SI} 4 \mathrm{H}-$ and $6 \mathrm{H}-\mathrm{SiC}$ is pinned at $E_{\mathrm{C}}=1.076$ and $E_{\mathrm{C}}=0.81 \mathrm{eV}$, respectively. The carrier density was calculated from the Fermi level:

$n_{0}=N_{\mathrm{C}} \exp \left(-\frac{E_{\mathrm{C}}-E_{\mathrm{F}}}{k_{0} T}\right)$,

where the density of states in the conduction band $N_{\mathrm{C}}$ is defined as

$N_{\mathrm{C}}=2 M_{\mathrm{C}}\left(2 \pi m^{*} k_{0} T / h^{2}\right)^{3 / 2}$,

where $M_{\mathrm{C}}$ is the number of conduction band minimum and $m^{*}$ is the electron effective mass. $M_{\mathrm{C}}$ was taken to be 3 for the $4 \mathrm{H}$ and 6 for the $6 \mathrm{H}$ materials [15]. The $m^{*}$ was taken to be 0.390 and 0.648 for the $4 \mathrm{H}$ and $6 \mathrm{H}$ materials, respectively [15].

The correlation between resistivity and carrier density is given by

$\rho=1 / n_{0} q \mu_{\mathrm{n}}$,

where $\mu_{\mathrm{n}}$ is electron mobility. In vanadium-doped SI $4 \mathrm{H}-$ and $6 \mathrm{H}-\mathrm{SiC}$, the electron mobilities at room temperature is about 100 and $30 \mathrm{~cm}^{2} /(\mathrm{V} \mathrm{s})$, respectively [16, 17]. The calculated resistivities of $4 \mathrm{H}-\mathrm{SiC}$ and $6 \mathrm{H}-\mathrm{SiC}$ are on the order of $1 \times 10^{15}-1 \times 10^{16}$ and $1 \times 10^{10}-1 \times$ $10^{11} \Omega \mathrm{cm}$, respectively, which is consistent with the measured resistivities in Fig. 2. 

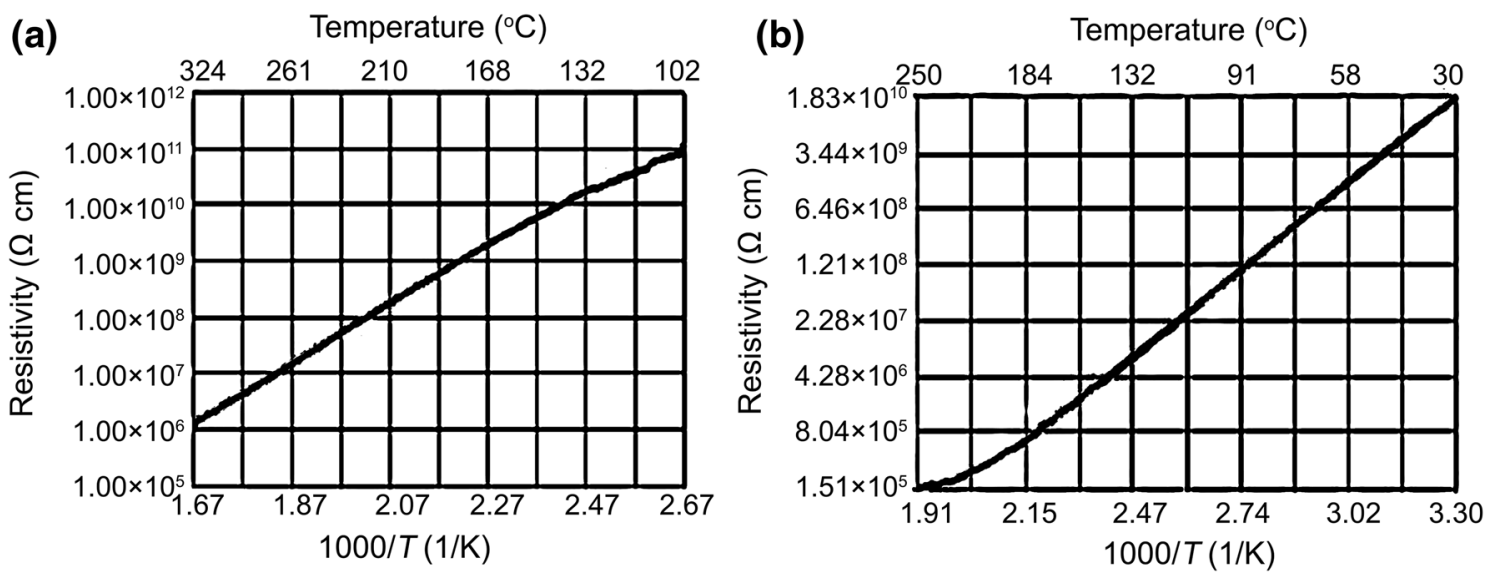

Fig. 4 Arrhenius plots of resistivity versus 1,000/T measured by COREMA-VT for $4 \mathrm{H}-\mathrm{SiC}$ wafer a $6 \mathrm{H}-\mathrm{SiC}$ wafer $\mathbf{b}$

To further analyze the anomalous resistivity in vanadium-doped SI $4 \mathrm{H}-\mathrm{SiC}$ wafers with $6 \mathrm{H}$ polytype inclusion, the compensation mechanism for the formation of anomalous resistivity was considered. Early work [18-20] proposed that vanadium substitutes for $\mathrm{Si}$ in the $\mathrm{SiC}$ lattice in one of three charge states, $\mathrm{V}_{\mathrm{Si}}^{3+}\left(3 d^{2}\right), \mathrm{V}_{\mathrm{Si}}^{4+}\left(3 d^{4}\right)$, and $\mathrm{V}_{\mathrm{Si}}^{5+}\left(3 d^{5}\right)$. Since the neutral state is the $\mathrm{V}^{4+}$ state, vanadium is amphoteric in $\mathrm{SiC}$, acting as either a donor, $\mathrm{V}^{4+/ 5+}$, or an acceptor, $\mathrm{V}^{3+/ 4+}$. The compensation is provided by either the acceptor or donor level of vanadium, depending on whether the residual background is $n$ type or $p$-type. Vanadium-doped SI SiC is often grown by PVT. In the crystal growth procedure, the growth proceeds via the crystallization of $\mathrm{Si}$ and $\mathrm{C}$ vapor species on a $\mathrm{SiC}$ seed crystal [21]. For the growth furnace, the power was supplied by an induction-heated system. The internal hot zone of the furnace consists of graphite crucible, porous graphite thermal insulation which was loaded in a cold-wall quartz containment vessel [22]. Since nitrogen, the primary active donor impurity in $\mathrm{SiC}$, always exists in the growth environment and is rather difficult to eliminate completely, the residual background is $n$-type. Secondary ion mass spectrometry (SIMS) was employed to determine the concentrations of donors (mainly nitrogen), acceptors (mainly boron and aluminum) and vanadium in the samples. The nitrogen $\left(N_{\mathrm{N}}\right)$, boron $\left(N_{\mathrm{B}}\right)$, and aluminum $\left(N_{\mathrm{Al}}\right)$ concentrations were about $4.3 \times 10^{17}, 1.1 \times$ $10^{17}$, and $5.6 \times 10^{16} \mathrm{~cm}^{-3}$, respectively. The vanadium $\left(N_{\mathrm{V}}\right)$ concentration was about $3.8 \times 10^{17} \mathrm{~cm}^{-3}$. Since $N_{\mathrm{V}}>N_{\mathrm{N}}-\left(N_{\mathrm{B}}+N_{\mathrm{Al}}\right)$ and $N_{\mathrm{N}}>\left(N_{\mathrm{B}}+N_{\mathrm{Al}}\right)$, the Fermi level would be pinned at the vanadium acceptor level $\mathrm{V}^{3+/ 4+}$ [13]. As the vanadium acceptor level $\mathrm{V}^{3+/ 4+}$ is located at different positions in the bandgap of $4 \mathrm{H}-\mathrm{SiC} \quad\left(E_{\mathrm{C}}=\right.$ $1.076 \mathrm{eV})$ and $6 \mathrm{H}-\mathrm{SiC}\left(E_{\mathrm{C}}=0.81 \mathrm{eV}\right)$, the resistivity difference between the $4 \mathrm{H}$ area and the $6 \mathrm{H}$ polytype inclusion area in vanadium-doped $\mathrm{SI} 4 \mathrm{H}-\mathrm{SiC}$ wafers is apparent.
Since the resistivity of the $4 \mathrm{H}$ area and the $6 \mathrm{H}$ polytype inclusion area in vanadium-doped SI 4H-SiC wafers exhibits a significant difference, the anomalous resistivity in vanadium-doped $\mathrm{SI} 4 \mathrm{H}-\mathrm{SiC}$ can be used to identify polytype inclusions.

Figure 5 shows the Raman spectra of another vanadiumdoped SI $4 \mathrm{H}-\mathrm{SiC}$ wafer with both $6 \mathrm{H}$ and $15 \mathrm{R}$ polytypes. Figure 5a shows the Raman mapping fitted by the peak positions of FTA bands, and Fig. 5b shows the Raman spectra corresponding to points $\mathrm{A}, \mathrm{B}$, and $\mathrm{C}$ in Fig. 5a. From the FTA modes (marked by blue arrows in Fig. 5b), it can be seen from Fig. 5a that the red, green, and blue areas belong to $4 \mathrm{H}, 6 \mathrm{H}$, and $15 \mathrm{R}$ polytypes, respectively.

Figure 6 is the resistivity mapping of the wafer as shown in Fig. 5. Combining Fig. 6 with Fig. 5a, it can be seen that the resistivities of $6 \mathrm{H}$ and $15 \mathrm{R}$ polytype areas are in the range of $1 \times 10^{10}-1 \times 10^{11}$ and $1 \times 10^{11}-1 \times 10^{12} \Omega \mathrm{cm}$, respectively. The resistivity in $4 \mathrm{H}-\mathrm{SiC}$ area exceeds $1 \times 10^{12} \Omega \mathrm{cm}$. Therefore, it is easy to identify $6 \mathrm{H}$ and $15 \mathrm{R}$ polytype inclusions from the resistivity mapping of vanadium-doped SI 4H-SiC. It will improve measurement efficiency for vanadium-doped $\mathrm{SI} 4 \mathrm{H}-\mathrm{SiC}$ mass production.

\section{Conclusions}

In vanadium-doped $\mathrm{SI} 4 \mathrm{H}-\mathrm{SiC}$ grown by $\mathrm{PVT}$, polytype inclusions result in the anomalous resistivity. Using activation energies measured by COREMA-VT, the resistivities of different polytypes were calculated, which are quite consistent with the measured resistivities. For the formation of anomalous resistivity, the compensation mechanism was proposed. The Fermi level is pinned at vanadium acceptor level $\mathrm{V}^{3+/ 4+}$ located at a different position in the bandgap of $4 \mathrm{H}-\mathrm{SiC} \quad\left(E_{\mathrm{C}}=1.076 \mathrm{eV}\right)$ or $6 \mathrm{H}-\mathrm{SiC}$ $\left(E_{\mathrm{C}}=0.81 \mathrm{eV}\right)$, which directly results in the resistivity 

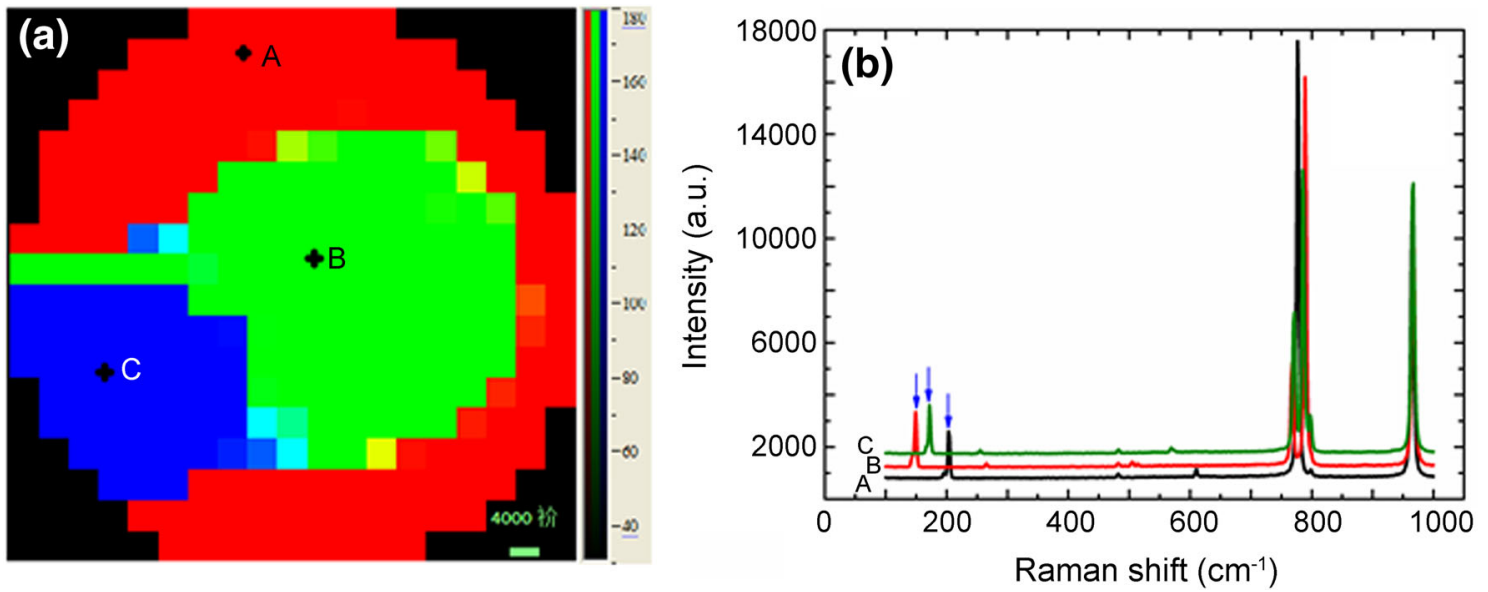

Fig. 5 Raman mapping of $4 \mathrm{H}-\mathrm{SiC}$ wafer with both $6 \mathrm{H}$ and $15 \mathrm{R}$ polytype inclusions a and Raman spectra corresponding to positions $A, B, C$ in a, b

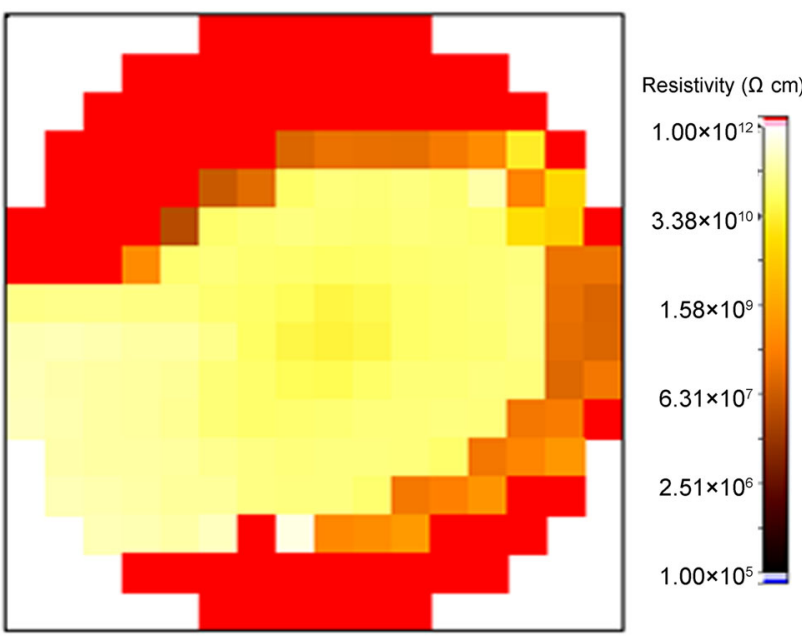

Fig. 6 Resistivity mapping of $4 \mathrm{H}-\mathrm{SiC}$ wafer with both $6 \mathrm{H}$ and $15 \mathrm{R}$ polytype inclusions

difference between the $4 \mathrm{H}$ single crystal and the $6 \mathrm{H}$ polytype inclusion areas in vanadium-doped SI $4 \mathrm{H}-\mathrm{SiC}$ wafers.

Acknowledgments This work was financially supported by National Basic Research Program of China (No. 2011CB301904) and the Natural Science Foundation of China (Nos. 11134006 and 61327808).

\section{References}

[1] R. Madar, Nature 430, 974 (2004)

[2] H.K.E. Latha, A. Udayakumar, V. Siddeswara Prasad, Acta Metall. Sin. (Engl. Lett.) 27, 168 (2014)
[3] R.S. Wei, S. Song, K. Yang, Y.X. Cui, Y. Peng, X.F. Chen, X.B. Hu, X.G. Xu, J. Appl. Phys. 113, 053503 (2013)

[4] S. Yamada, B.S. Song, T. Asano, S. Noda, Appl. Phys. Lett. 99, $201102(2011)$

[5] S. Nakashima, H. Harima, Phys. Status Solidi A. 162, 39 (1997)

[6] M. Bickermann, R. Weingärtner, A. Winnacher, J. Cryst. Growth 254, 390 (2003)

[7] J. Schneider, H.D. Muller, K. Meier, W. Wilkening, F. Fuchs, A. Dornen, S. Leibenzeder, R. Stein, Appl. Phys. Lett. 56, 1184 (1990)

[8] A. Dornen, Y. Latushko, W. Suttrop, G. Pensl, S. Leibenzeder, R. Stein, Mater. Sci. Forum 83-87, 1213 (1992)

[9] W.C. Mitchel, W.D. Mitchell, G. Landis, H.E. Smith, W.W. Lee, M.E. Zvanut, J. Appl. Phys. 101, 013707 (2007)

[10] E. Tymicki, K. Grasza, R. Bozek, M. Gata, Cryst. Res. Technol. 42, 1232 (2007)

[11] S. Limpijumnong, W.R.L. Lambrecht, Phys. Rev. B 57, 12017 (1998)

[12] F.Y. Chen, E.D. Delber, Acta Metall. Sin. (Engl. Lett.) 12, 633 (1999)

[13] D.W. Feldman, J.H. Parker, W.J. Choyke, L. Patrick, Phys. Rev. 170, 698 (1968)

[14] D.W. Feldman, J.H. Parker, W.J. Choyke, L. Patrick, Phys. Rev. 173, 787 (1968)

[15] C. Persson, U. Lindefelt, J. Appl. Phys. 82, 5496 (1997)

[16] Q. Li, A.Y. Polyakov, M. Skowronski, J. Appl. Phys. 96, 411 (2004)

[17] M. Bickermann, R. Weingärtner, A. Winnacker, J. Cryst. Growth 390, 254 (2003)

[18] J. Schneider, H.D. Müller, K. Maier, W. Wilening, F. Fuchs, A. Dörnen, S. Leibenzeder, R. Stein, Appl. Phys. Lett. 56, 1184 (1990)

[19] K. Maier, H.D. Müller, J. Schneider Mater. Sci. Forum 83-87, 1183 (1992)

[20] K. Maier, J. Schneider, W. Wilening, A. Leibenzeder, R. Stein, Mater. Sci. Eng. B 11, 27 (1992)

[21] H.M. Hobgood, D.L. Barrett, J.P. McHugh, R.C. Clarke, S. Sriram, A.A. Burk, J. Greggi, C.D. Brandt, R.H. Hopkins, W.J. Choyke, J. Cryst. Growth 137, 181 (1994)

[22] D.L. Barrett, R.G. Seidensticker, W. Gaida, R.H. Hopkins, W.J. Choyke, J. Cryst. Growth 109, 17 (1991) 